\title{
IMPACT OF TECHNOLOGY ENHANCED(VIDEO-ASSISTED) TEACHING AS A TEACHING-LEARNING TOOL FOR MBBS FINAL II STUDENTS
}

\author{
Medical Science \\ Dr Gurdit Singh \\ Randhawa* \\ Professor of surgery, MMUISMR, Mullana, Distt. Ambala. *Corresponding Author
}

\section{Dr Navneet singh Randhawa}

Lecturer In Periodontics And Oral Implantology, MMUISMR, Mullana, Distt. Ambala.

\section{ABSTRACT}

Introduction: Traditional TL methods like writing on blackboard and now powerpoint presentations are increasingly becoming old fashioned, less interesting for technology savvy present generation of students. More advanced and attention seeking methods of teaching are expected by students in tandem with their excursions with technology. Here a comparative study of video-assisted teaching $\mathrm{v} / \mathrm{s}$ power point presentation compared as students' feedback after exposing them to both methods alternately.

Aim And Objectives: To find out the impact of video assisted teaching against power point teaching.

Methodology: The study was carried out with the M.B.B.S. Final II year students in the Department of Surgery, Punjab Institute of Medical Sciences, Jalandhar. After taking IEC clearance, students were sensitized. A total of 122 final MBBS II Students were enrolled in study. They were divided into two groups; group A and group B. They were exposed to both methods of teaching (Method 1: video assisted learning and Method 2:power point presentation) individually in two sessions. During 2nd session, cross over was done. Feedback questionnaire was distributed after a 15 minutes session every time. The feedback reports were selected from each group and data analysed.

Observations: Students who were subjected to video assisted teaching voted overwhelmingly in favour of it while those who were demonstrated the procedure through power points gave a lukewarm response about power point style of teaching. Most suggestions and remarks directed in favour of video assisted teaching . They opined that it will help them in understanding the subject in great way. $62.20 \%$ could write all four steps correctly of procedure at the end of session in group $\mathrm{A}$ (just taught by video) while only $31.10 \%$ could do so in group $\mathrm{B}$ (taught by power point . Conclusion: Teaching through video assistance, especially surgical procedures results in better attention and retaining of teaching material than with traditional power point teaching which students found non attentive.

\section{KEYWORDS}

Impact, Video-assisted Learning, Feedback, Cognitive Skills, Students.

\section{INTRODUCTION-}

Making a group of students attentive to teacher remains a herculean task since time immemorial. Training of any kind was associated with harsh punishment for non-learners with consequence of discontinuation of education by pupils/students. Over the time there happened much refinement in educational system with incorporation of available latest technologies. During the last two decades of $20^{\text {th }}$ century there was rapid development of technology including computer and its vast use. ${ }^{[1]}$ Application of which did not remain confined to select few areas. Education system probably benefitted most from this technological advancement, especially in the areas of research. Traditional TL methods like writing on blackboard and now powerpoint presentations are increasingly becoming old fashioned. Students feel that it is non-attentive and most learning material goes overhead with only a fraction of teaching material is retained by them. Constant efforts and innovations are made globally to break this monotony for technology saavy present day generation of students. More advanced and attention seeking methods of teaching are expected by students in tandem with their excursions with technology. Many new techniques are developed including video-assisted teaching-learning (TL) methods with encouraging results. Though it needs extra effort including resources and inclusion of trained faculty and associated personnel, the idea of technology enhanced learning is worth implementing where an institution doesn't have any resource constraints. ${ }^{[2]}$ Here is a comparative analysis of video-assisted teaching $\mathrm{v} / \mathrm{s}$ power point presentation compared as students' feedback after exposing them to both methods alternately.

\section{AIM \& OBJECTIVES \\ Aim:}

\#To study the impact of video-assisted method of Technology Enhanced Learning (TEL) on final year II MBBS students.

\#To improve the attentive and retaining capacity of students through audiovisual style of teaching.

\section{Specific Objectives:}

- To find out the impact of video assisted teaching against traditional power point presentation for attentiveness and retention of learning material.

\section{METHODOLOGY}

After getting the plan of study approved from the authorities at Nodal centre for Advanced Course in Medical Education (ACME), CMC, Ludhiana; the project plan was submitted for approval from ethics committee of Punjab Institute of Medical Sciences (PIMS), Jalandhar. Once the project was cleared a move for sensitization of students and faculty was started. After taking them in confidence resources like videography, feedback form printing etc. were done. A total of 122 final MBBS II Students were enrolled in the study. They were divided into two groups; group A and group B. Both the groups were exposed to both methods of teaching individually in two sessions. During first session 61 students of group A were shown videography of open appendicectomy without any sound in video. Teacher was giving commentary on the contents(steps of the procedure) of the video . At the end of video session feedback form for feedback was distributed . Students took 10 minutes to fill the feedback form and deposited it back. Meanwhile, the group B students waited outside. Once group A finished they were asked to wait outside and group B students were taken inside the classroom. They were taught open appendicectomy in traditional powerpoint presentation for 15 minutes and asked to give a written feedback in feedback form. Once they finished class rejoined for attendance. During $2^{\text {nd }}$ session, group A was taught through power point and group B was taught through video. Second topic (video \& ppt.) was of open cholecystectomy. Feedbacks were taken on feedback form as on previous day. This way 122 feedback filled feedback form were there in each group. Data collected was analyzed on SPSS software.

\section{OBSERVATIONS AND RESULTS}

Separate master charts of data of groupA and group B were made and analysis of these data done on various parameters mentioned in feedback form. Following is the observation table-

\section{OBSERVATIONS}

Table-1: Students' Feedback Response Data

\begin{tabular}{|l|l|l|}
\hline QUESTION & RESPONSE & RESPONSE \\
\hline & GROUP A & GROUP B \\
\hline 1. How did you find & Good-60(49.3\%) & Good-70(57,3\%) \\
this way of teaching & Vg -58(47.5\%) & Vg-06(04.9\%) \\
Good(g),very & B-02(1.6\%) & B-32(26.2\%) \\
good(vg), bad(b) 0r & W-00(0.0\%) & W-02(1.6\%) \\
worst(w) & Non-responsive- & Non-responsive- \\
& $02(1.6 \%)$ & $12(9.8 \%)$ \\
\hline
\end{tabular}




\begin{tabular}{|l|l|l|}
\hline 2. Will it help you & Yes-106(86.8\%) & Yes-58(47.5\%) \\
understand the & No-04(3.2\%) & No-20(16.3\%) \\
subject in better way & Non-responsive- & Non-responsive- \\
Yes(y)/no(n) & $12(9.8 \%)$ & $44(36.0 \%)$ \\
\hline 3. Do you expect & Yes-104(85.2\%) & Yes-56(45.9\%) \\
such method for & No-08(3.2\%) & No-36(29.5\%) \\
other subjects too? & Nonresponsive- & Non-responsive- \\
Yes(y)/no(n) & $14(11.4 \%)$ & $30(24.5 \%)$ \\
\hline 4. four steps of & $++++=76(62.2 \%)$ & $++++=38(31,1 \%)$ \\
procedure & $+++=34(27.8 \%)$ & $+++=38(31.1 \%)$ \\
& $++=12(9.8 \%)$ & $++=24(19.6 \%)$ \\
& $+=$ nil & $+=16((13.1 \%)$ \\
& Nil=nil & Nil=06(4.9\%) \\
\hline
\end{tabular}

Response to first question "How did you find this way of teaching" was overwhelmingly $\operatorname{good}(\mathrm{G})(\mathrm{n}=60,49.3 \%)$ and very good $(V g)(\mathrm{n}=58,47.5 \%)$ in favour of video assisted teaching while powerpoint teaching got response as good, better than video group $(\mathrm{n}=70,57.3 \%)$ but very good response was far low $(\mathrm{n}=06,04.9 \%)$ than video group. A substantial number of students $(n=32,26.2 \%)$ labeled the PPT method as $\operatorname{bad}(\mathrm{B})$ while only one $(01.6 \%)$ student labeled the video method as bad. Only one $(1.6 \%)$ student remained nonresponsive in video group while a significant number $(\mathrm{n}==12,9.8 \%)$ preferred to remain non-responsive. Only two $(1.6 \%)$ students in PPT group labelled the method as $\operatorname{worst}(\mathrm{W})$.

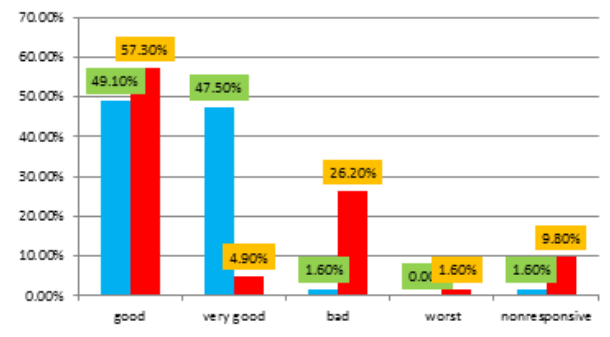

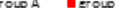
Graph-1: How Did You Find This Way Of Teaching; Good(g),very Good(vg), Bad(b) 0r Worst(w)(n=122 In Each Group)

In response to second question "will it help you understand the subject in better way?" group A students that is video group hugely $(\mathrm{n}=106(86.8 \%)$ responded as yes while only $04(3.2 \%)$ students gave no as the answer and $12(9.8 \%)$ students remained unresponsive at all.

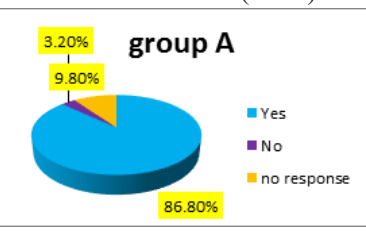

Graph-2: Will it help you understand the subject in better way; $\operatorname{Yes}(\mathbf{y}) / \mathrm{no}(\mathrm{n}) / \mathrm{no}$ response (groupA) $(n=122)$

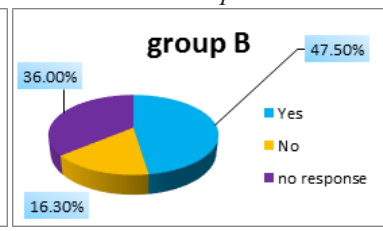

Graph-3: Will it help you understand the subject in betterway; $\operatorname{Yes}(\mathbf{y}) / \mathrm{no}(\mathrm{n}) / \mathrm{no}$ respons (groupB) $(\mathbf{n}=\mathbf{1 2 2})$.
Group B gave a lukewarm response only $47.5 \%(\mathrm{n}=58)$ gave the answer in affirmation(yes) while $16.3 \%(\mathrm{n}=20)$ said no as their response and $36.0 \%(\mathrm{n}=44)$ did not respond (non-responsive).

Response to third question was as follows "Do you expect such method for other subjects too?" The response was again in favor of video assisted teaching. In Group A 85.2\% $(\mathrm{n}=104)$ said yes while only $3.2 \%(\mathrm{n}=04)$ responded in negative $(n o) .11 .4 \%(\mathrm{n}=07)$ remained unresponsive. In group B $45.9 \%(\mathrm{n}=56)$ said yes while $29.5 \%(\mathrm{n}=36)$ said no. $24.5 \%(\mathrm{n}=30)$ preferred not to respond(unresponsive).

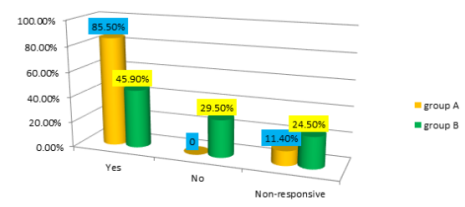

Graph-5 Do You Expect Such Method For Other Subjects Too?(n=122 In Each Group)
All data shows an overwhelming positive tilt towards video assisted teaching. Comments and remarks too favour video assisted teachinglearning method and a significant disliking for power point presentation. Last question was "write down four steps of procedure just described?" $62.2 \%(\mathrm{n}=76)$ wrote correct steps of group A while $31.1 \%(\mathrm{n}=38)$ could manage to write right steps in group $\mathrm{B}$. with a marginal difference $27.8 \%(n=34)$ in group $A$ and $31,1 \%$ in group could answer three steps correctly.

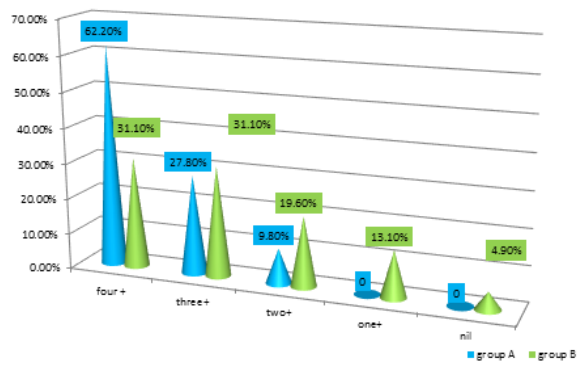

Graph-4: Four Steps Of Procedure ( N=122 In Each Group)

\section{DISCUSSION}

The use of technology to maximise the student learning experience is a vibrant area of interest across all spheres of global education. Technology enhanced learning (TEL) is often used as synonymous for e-learning but can also be used to refer to technology enhanced classrooms and learning with technology.Learning (whether traditional, e-learning, or blended learning) is closely related to and dependent on the human cognitive system. Learning means that the cognitive system acquires information and stores it for further use. ${ }^{[3]}$ If these processes do not occur properly, then the learners will not initially acquire the information, and even if they do, then they will not be able to recall it later, and/or the information will not be utilised and behaviour will not be modified. In present study students gave their preference to video assisted teaching shows that the present day technologically well versed student wants a change from traditional teaching to technologically advanced methods of teaching which can go well with their sound knowledge of technology and internet. ${ }^{[4]}$ The spontaneous preference for TEL can be gauzed from the fact that a good percentage $(62.2 \%, \mathrm{n}=76)$ could answer last question (four steps of just taught surgical procedure) correctly in group A while just half $(31.1 \%, \mathrm{n}=38)$ could manage so in group B that is traditional PPT presentation. Suggestions like "there should be more and more video assisted classes", "this method is very good" "this type of teaching should be implemented permanently" "very good way of teaching especially in case of showing surgeries" these are some of many suggestions given by group A students in favour of video assisted teaching. In contrast suggestions by group B are "first it should be taught theoretically then video" "video must be collaborated simultaneously" "video for surgery are better" "a combined approach of video+slides should be tried" reflect that students simply dislike the traditional ways of teaching when they are using advanced technology in every other activity be it mobile phone, banking, skypes etc. response to another question "will it help you in understanding the subject better? "was further amazing when $86.8 \%(\mathrm{n}=106)$ of group $\mathrm{A}$ candidates responded in affirmation while only $46.5 \%(\mathrm{n}=58)$ said yes in group B. Despite the fact that video quality was ordinary, response in favour was astonishingly good as silent video was combined with commentary by the teacher. On other hand powerpoint presentation was full of illustrations and sketches with good quality slides, still the method got a lukewarm response. Many earlier studies especially those done by Dror I.E. et al are showing similar results which are reproduced many times by Dror I.E. himself and others. He has also pointed out many flaws in this new teaching learning method and pointed out areas requiring further improvement. ${ }^{[2,3,4,5]}$ Ayinde,A.T. in 'Let's use video reinvent education' describes the transformative way video can impact on teaching and learning and encourages teachers to consider the flipped classroom model where learners can digest lecture content at their pace and explore content more deeply during class time ${ }^{[7]}$. Dror IE used video-assisted teaching to minimize errors in cognitive learning ${ }^{[8]}$. Shepard et al and Mayer et almade the connection between visual clues, the memory process, and the recall new-knowledge ${ }^{[9][10]}$. Allam observedthat the creative challenge of using moving images and sound to communicate a topic indeed engaging and insightful, but adds that it also enables 
students to acquire a range of transferable skills to learners ${ }^{[11]}$. In some cases, video can be as good as an instructor in communicating facts or demonstrating procedures to assist in mastery learning where a student can view complex clinical or mechanical procedures as many times as they need to. Furthermore, the interactive features of modern web-based media players can be used to promote "active viewing"approaches with students $^{[12]}$ Fakhry A. and Packer ME et al used videos and plasmascreens for teaching procedures to undergraduate students odentistrywith very encouraging results ${ }^{[14][15]}$.

\section{Outcomes: What This Study Adds:}

present study endorses the new method of video assisted teaching slowly getting popular in many parts of globe. Can be very useful as cognitive tool for improvement in attention and better understanding of the teaching material especially procedure description related topics.

\section{Limitations:}

Apart from various advantages of this method, it carries following limitations-

1, Lack of teacher-student interaction, thus remains a passive noninteractive teaching despite being a high-tech one.

2. Cannot be instituted without specific resources and trained faculty thus resisted by institutional authorities to avoid extra expenses.

3. Time consuming and technologically demanding.

4. Short-term study on small number of students.

\section{CONCLUSION}

Learning means that the cognitive system acquires information and stores it for further use. If these processes do not occur properly, then the learners will not initially acquire the information or if at all he manages to acquire a part of it the ultimate goal of using it purposefully will not be solved. To achieve this many modifications are done throughout in past to enhance the understanding and retaining capacity of learners. Of late technological advancement is being tried for the same purpose. Present study too is an attempt to reproduce the work of earlier researches. Highly encouraging results are obtained with some limitations like- short term study on just one group of students, lack of student- teacher interaction and time consuming and technologically demanding. Still the work gives an indication for future research on the subject to make it more reliable and valid to be included in regular curriculum especially for procedural demonstrations.

\section{IMPLICATIONS-}

This study with encouraging results may ultimately become part of curriculum because of its merits over traditional teaching; especially for teaching of procedure related demonstrations as the experiments on animals is a thing of the past. This method can be an alternative of it. Moreover, surgical procedures can be made better understandable by showing video of procedure along with commentary by the teacher. A combination of video+ interactive discussion can be further helpful in enhancing the learning. ${ }^{[2]}$ Especially to demonstrate dissections, various experiments and demonstrations in paraclinical subjects and surgical procedures in clinical subjects.

\section{REFERENCES}

1. Aleven V, Koedinger K. An effective metacognitive strategy: Learning by doing and explaining with a computer-based cognitive tutor. Cogn Sci, 2002; 26(2)147-1818.

2. Dror IE, Stevenage SV, Ashworth A. Helping the cognitive system learn: Exaggerating distinctiveness and uniqueness. Appl Cogn Psychol 2008; 22(4)573-584.

3. Dror IE. Brain friendly technology: what is it? And why do we need it? In: Dror editor. John Benjamins, Technology enhanced learning and cognition, Amsterdam 2011

Dror IE, Harnad S, eds. 2008. Cognition distributed: how cognitive technology extends our minds. (258 pp.) John Benjamins, Amsterdam.

5. Dror IE. Technology enhanced learning: The good, the bad, and the ugly. Pragmatics Dror IE. Technology enha
Cogn 2008; 16(2)215-223

6. Dror IE, ed. 2011a. Technology enhanced learning and cognition. Amsterdam: John Benjamins1]

7. Ayinde, A.T. Resources for Effective Teaching and Learning of Agricultural Science, Bichi Journal of Education and Planning 1997; 1(1):6-8

8. Dror IE. A novel approach to minimize error in the medical domain: Cognitive neuroscientific insights into training. Med Teach, 2011b; 33(1)34-38

. Shepard, R. \&Cooper, L. Mental images and their transformations, MIT Press/Bradford Books, Cambridge,MA1982

10. Mayer, R., Gallini, J.'When is an illustration worth ten thousand words?' Journal Mayer, R., Gallini, J.'When is an illustration wort
of Educational Psychology1990 82(6): 715-726

11. Allam, C. in Bijnens, MVanbuel, M., Verstegen, S., Young C., Handbook on Digital Video and Audio in Education, Creating and using audio and video material for educational purposes, The Videoakt Project2006

12. Galbraith, J.'Active viewing: and oxymoron in videobased instruction?', Society for Applied LearningTechnologies Conference2004

13. Kleffner DA, Ramachandran VS. On the perception of shape from shading. Percept Psychophys 1992; 52: 18-36.

14. Fakhry A, Dehkordi-Vakil FH. Video-Assisted Clinical Instruction in Dentistry
(VACID) enhances real-time visualisation of clinical procedures. Eur J Dent Educ. 2007;11(4):238-44.

15. Packer ME, Coward TJ, Wakeley R, Fenlon MR. A preliminary study to investigate the potential of plasma screen technology in small group teaching for dental undergraduates. Eur J Dent Educ. 2003;7(3):136-42. 